\title{
(6) OPEN ACCESS \\ Occupational exposure to textile dust increases the risk of rheumatoid arthritis: results from a Malaysian population-based case-control study
}

\author{
Chun Lai Too, ${ }^{1,2}$ Nor Asiah Muhamad, ${ }^{1}$ Anna llar, ${ }^{3}$ Leonid Padyukov, ${ }^{2}$ \\ Lars Alfredsson, ${ }^{3}$ Lars Klareskog, ${ }^{2}$ Shahnaz Murad, ${ }^{1}$ Camilla Bengtsson, ${ }^{3}$ \\ MyEIRA Study Group
}

\begin{abstract}
Handling editor Tore K Kvien
${ }^{1}$ Institute for Medical Research, Jalan Pahang, Kuala Lumpur, Malaysia

${ }^{2}$ Rheumatology Unit, Department of Medicine, Center for Molecular Medicine L8:04, Karolinska University Hospital, Stockholm, Sweden 3 Institute of Environmental Medicine, Karolinska Institutet, Stockholm, Sweden
\end{abstract}

\section{Correspondence to} Dr Chun Lai Too Allergy and Immunology Research Center, Institute for Medical Research, Jalan Pahang, 50588 Kuala Lumpur, Malaysia; toocl@imr. gov.my, chunlai.too@ki.se; and Dr Camilla Bengtsson, Institute of Environmental Medicine, Karolinska Institutet, Nobels väg 13, Box 210, 17177 Stockholm, Sweden; camilla.bengtsson@ki.se

Received 21 July 2015 Revised 25 September 2015 Accepted 18 October 2015 Published Online First 17 December 2015

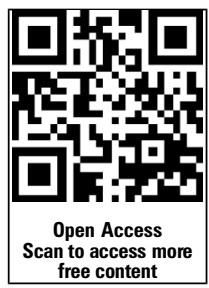

\section{CrossMark}

To cite: $\mathrm{Too} C \mathrm{~L}$

Muhamad NA, llar A, et al. Ann Rheum Dis

2016:75:997-1002.

\section{ABSTRACT}

Objectives Lung exposures including cigarette smoking and silica exposure are associated with the risk of rheumatoid arthritis (RA). We investigated the association between textile dust exposure and the risk of RA in the Malaysian population, with a focus on women who rarely smoke.

Methods Data from the Malaysian Epidemiological Investigation of Rheumatoid Arthritis population-based case-control study involving 910 female early RA cases and 910 female age-matched controls were analysed. Self-reported information on ever/never occupationally exposed to textile dust was used to estimate the risk of developing anti-citrullinated protein antibody (ACPA)positive and ACPA-negative RA. Interaction between textile dust and the human leucocyte antigen DR $\beta$-1 (HLA-DRB1) shared epitope (SE) was evaluated by calculating the attributable proportion due to interaction (AP), with 95\% Cl.

Results Occupational exposure to textile dust was significantly associated with an increased risk of developing RA in the Malaysian female population (OR 2.8, 95\% Cl 1.6 to 5.2). The association between occupational exposure to textile dust and risk of RA was uniformly observed for the ACPA-positive RA (OR 2.5, 95\% Cl 1.3 to 4.8) and ACPA-negative RA (OR 3.5, $95 \%$ Cl 1.7 to 7.0 ) subsets, respectively. We observed a significant interaction between exposure to occupational textile dust and HLA-DRB1 SE alleles regarding the risk of ACPA-positive RA (OR for double exposed: 39.1, $95 \% \mathrm{Cl} 5.1$ to $297.5 ; \mathrm{AP}: 0.8,95 \% \mathrm{Cl} 0.5$ to 1.2 ). Conclusions This is the first study demonstrating that textile dust exposure is associated with an increased risk for RA. In addition, a gene-environment interaction between HLA-DRB1 SE and textile dust exposure provides a high risk for ACPA-positive RA.

\section{INTRODUCTION}

Rheumatoid arthritis (RA) is a multifactorial disease that involves the interaction between environmental and genetic factors. ${ }^{1-7}$ Smoking is one of the most established risk factors for disease development, ${ }^{7-11}$ and a profound interaction between smoking and human leucocyte antigen DR $\beta-1$ (HLA-DRB1) shared epitope (SE) alleles regarding the risk of anti-citrullinated peptide antibody (ACPA)-positive RA has been reported in several studies. ${ }^{1} 278$ 12-16 There is growing support for the hypothesis that this gene-environment interaction may induce changes in the lung tissues, where immunity against citrullinated antigens may be triggered in individuals with certain genotypes. ${ }^{1} 7$ 17-19

Silica is another lung exposure that has been associated with the risk of ACPA-positive, ${ }^{20} 21$ indicating that exposure to other noxious agents than smoke in the lung may provide a risk for RA. Exposure to textile dust has been shown to impair the lung functions of workers ${ }^{22-25}$ and increase the risk of respiratory diseases, ${ }^{22} 2627$ but whether it is involved in RA development remains to be elucidated. The investigation of genetic and environmental risk factors for RA in Malaysia (Malaysian Epidemiological Investigation of Rheumatoid Arthritis (MyEIRA)) $2128-32$ offers an opportunity to investigate the association between textile dust and RA risk.

In the present study, we specifically investigated whether occupational exposure to textile dust, which is common in Malaysia, may increase the risk of RA overall as well as the subsets of RA defined by ACPA status. We additionally explored the interaction between textile dust exposure and the HLA SE alleles in relation to the RA subsets.

\section{MATERIALS AND METHODS \\ Study base}

This study is based on the MyEIRA case-control study, a sister study to the Swedish EIRA study involving early RA cases. ${ }^{20}$ The study design of MyEIRA has been described in details elsewhere. $^{28} 32$ Briefly, study subjects aged between 18 and 70 years were recruited between 2005 and 2009 from a defined geographical area in Peninsular Malaysia. In this report, data from 910 female RA cases and 910 female controls were analysed. Male subjects were excluded as textile dust exposure among men was very scarce (two exposed cases among 155 male RA and one exposed control out of 150 male controls). Moreover, the smoking frequency was high among the men $(46 \%$ and $28 \%$ in male RA cases and male controls, respectively) but was very low among the women $(1 \%$ among cases and $0.4 \%$ among controls, respectively). ${ }^{2}$

\section{Case identification and selection of controls}

Patients with early RA were identified from nine rheumatology clinics throughout Peninsular 
Malaysia. All RA cases were diagnosed by rheumatologists and fulfilled the 1987 American College of Rheumatology (ACR) criteria. ${ }^{33}$ One control per RA case was randomly selected from the general population and matched on the age, sex and residential area. For the RA cases, the disease onset was defined at the time of having first symptoms giving suspicion of RA. The year in which these symptoms occurred was defined as the index year and the same index year was used for the corresponding control.

\section{Data collection and blood sampling}

Both RA cases and controls underwent a face-to-face interview by trained personnel to obtain information on lifestyle and environmental exposures using an identical questionnaire. The questionnaire comprised a wide range of questions on socioeconomic background, lifestyle, life events, working history, working conditions and exposures to chemicals or substances at work, including questions on textile and silica dust. Of the 1166 identified early RA cases, 1076 (92\%) completed the questionnaire. Of these 1076 RA cases, $85.6 \%(n=921)$ were females. Eleven of the female RA cases, however, did not have matched controls and were excluded from analysis. For the control subjects, a total of 1069 population-based controls participated by answering the questionnaire, and $86.0 \% \quad(n=919)$ were females. Nine of the females did not match any of the RA cases and thus were excluded from data analysis. Finally, data from 910 female RA cases and 910 age-matched and residential area-matched female controls were analysed in this study. Sera and DNA samples were obtained from all the participants for laboratory investigations.

\section{HLA-DRB1 genotyping and autoantibodies measurements}

The methods for determining the HLA-DRB1 alleles have previously been reported. ${ }^{28}$ In brief, the four-digit HLA-DRB1 genotyping was performed by using the LABType HD Class II DRB1 sequence specific oligonucleotide assay (One Lambda, California, USA) with the Luminex Multi-Analyte Profiling System (xMAP, Luminex Corporation, Texas, USA). The HLADRB1 SE alleles were defined as the presence of DRB1*01:01, DRB1*01:02, DRB1*01:07, DRB1*04:01, DRB1*04:04, DRB1*04:05, DRB1*04:08, DRB1*04:10, DRB1*10:01 and DRB1*10:03. Individuals with one or two SE alleles are categorised as SE-positive. ACPA status was assessed by using an anti-cyclic citrullinated peptide (anti-CCP) second-generation ELISA kits (Immunoscan RA, Malmö, Sweden). Samples with results $>25 \mathrm{AU} / \mathrm{mL}$ were defined as positive. ${ }^{28} 31$

\section{Assessment of exposures}

Participants were asked whether they had ever been exposed to textile dust at work. Individuals were classified as occupationally exposed to textile dust if they reported exposure before or during the index year. Individuals with missing information (53 female RA cases and 35 female controls) were excluded from the analysis (table 1).

\section{Potential confounding factors}

Age and residential area were design variables and adjusted for in the analysis. We considered smoking as a potential confounder, but there were only two female patients with RA who were ever smokers and none in the control group. In addition, formal educational level (categorised as no formal education, primary education, secondary education or college/university) and ethnicity (categorised as Malay, Chinese, Indian and others) were adjusted for in all analyses, but these factors only marginally
Table 1 Characteristics of female rheumatoid arthritis (RA) cases and female controls in the Malaysian Epidemiological Investigation of Rheumatoid Arthritis (MyEIRA) study

\begin{tabular}{|c|c|c|}
\hline & $\begin{array}{l}\text { Female RA cases } \\
(n=910)\end{array}$ & $\begin{array}{l}\text { Female controls } \\
(n=910)\end{array}$ \\
\hline Mean age (SD) & $47.5(11.4)$ & $47.4(11.3)$ \\
\hline \multicolumn{3}{|l|}{ Ethnicity } \\
\hline Malay & $381(41.9)$ & $591(65.0)$ \\
\hline Chinese & $182(20.0)$ & $105(11.5)$ \\
\hline Indian & $307(33.7)$ & $159(17.5)$ \\
\hline Others & $40(4.4)$ & $55(6.0)$ \\
\hline \multicolumn{3}{|l|}{ Educational level } \\
\hline No formal education & $41(4.5)$ & $64(7.0)$ \\
\hline Primary education & $202(22.2)$ & $222(24.4)$ \\
\hline Secondary education & $479(52.6)$ & $444(48.8)$ \\
\hline College/university & $184(20.2)$ & $177(19.5)$ \\
\hline Missing information & $4(0.4)$ & $3(0.3)$ \\
\hline \multicolumn{3}{|l|}{ ACPA } \\
\hline Positive & $575(63.2)$ & $18(2.0)$ \\
\hline Negative & $325(36.8)$ & $892(98.0)$ \\
\hline \multicolumn{3}{|l|}{ HLA-DRB1 SE alleles } \\
\hline Positive & $360(39.6)$ & $147(16.0)$ \\
\hline Negative & $549(60.3)$ & $763(84.0)$ \\
\hline Missing information & $1(0.1)$ & 0 \\
\hline \multicolumn{3}{|l|}{ Smoking habits } \\
\hline Never smoker & 870 (95.6) & $884(97.2)$ \\
\hline Ever smoker & $9(1.0)$ & $4(0.4)$ \\
\hline Missing information & $31(3.4)$ & $22(2.4)$ \\
\hline \multicolumn{3}{|l|}{ Textile dust exposure } \\
\hline Occupational exposed & $41(4.5)$ & $15(1.7)$ \\
\hline Unexposed & $622(68.4)$ & $647(71.1)$ \\
\hline Missing information & $53(5.8)$ & $35(3.8)$ \\
\hline
\end{tabular}

ACPA, anti-citrullinated peptides antibody; HLA-DRB1 SE, human leucocyte antigen DR $\beta-1$ chain shared epitope.

changed the results and were therefore not retained in the final analysis.

\section{Statistical analysis}

In the present study, only data on occupational exposure before and during the index year have been analysed. Subjects who had ever been exposed to occupational textile dust were compared with those unexposed regarding risk of developing RA, ACPA-positive RA and ACPA-negative RA. The ORs with 95\% CIs were calculated by means of unconditional logistic regression. Possible interaction between textile dust exposure and HLA-DRB1 SE alleles was evaluated as departure from additivity by calculating the attributable proportion due to interaction (AP), with $95 \% \mathrm{CI}^{44}$ Analyses were conducted using Stata V.12.0.

\section{RESULTS}

\section{Characteristics of the MyEIRA subjects}

In this report, we analysed a total of 910 female RA cases and 910 female population-based controls. The median duration of time from disease onset to enrolment in the study was 1 year, with an IQR of 2 years. The distribution of ethnic groups (Malay, Chinese, Indian and other subethnicities) is presented in table 1. The proportion of ACPA positivity and HLA-DRB1 SE 
alleles carriage among the female patients with RA were $63.2 \%$ and $39.6 \%$, respectively. Occupational exposure to textile dust was reported by $4.5 \%$ of the female patients with RA $(n=41$, whereof Malay=14, Chinese $=11$, Indian=13 and other $=3$ ) and by $1.7 \%$ of the women in the control group $(n=15$, whereof Malay $=6$, Chinese $=5$, Indian $=3$ and other $=1$ ).

\section{Textile dust and the risk of developing ACPA-positive and ACPA-negative RA}

Those exposed to occupational textile dust had an increased risk of developing RA compared with unexposed individuals (OR 2.8, 95\% CI 1.6 to 5.2). Furthermore, our findings demonstrated that occupational exposure to textile dust was significantly associated with increased risk for both ACPA-positive RA (OR 2.5, 95\% CI 1.3 to 4.8) and ACPA-negative RA (OR 3.5, 95\% CI 1.7 to 7.0 ) (table 2).

\section{Interaction between occupational textile dust exposures and HLA-DRB1 SE alleles}

An increased risk of ACPA-positive RA was seen among carriers of HLA-DRB1 SE alleles who were exposed to occupational textile dust compared with non-carriers of SE alleles not exposed to textile dust (OR 39.1, 95\% CI 5.1 to 297.5) (table 3 and figure 1). We observed a significant interaction between HLA-DRB1 SE alleles and occupational exposure to textile dust with regard to risk of ACPA-positive $\mathrm{RA}(\mathrm{AP}=0.8,95 \% \mathrm{CI} 0.5$ to 1.2). The combination of occupational exposure to textile dust and HLA-DRB1 SE alleles was also associated with an increased risk of ACPA-negative RA (OR 9.3, 95\% CI 1.0 to 89.4), but no statistical significant interaction was observed $(\mathrm{AP}=0.6,95 \% \mathrm{CI}-0.4$ to 1.6$)$ (table 3$)$.

\section{DISCUSSION}

We observed that occupational exposure to textile dust was associated with an increased risk of ACPA-positive and ACPA-negative RA among Malaysian women. Additionally, a statistically significant interaction between occupational textile dust exposure and presence of HLA-DRB1 SE alleles was seen concerning risk to develop ACPA-positive RA.

We note that the association between textile dust exposure and risk for RA differs from what has previously been observed for smoking and silica as textile dust exposure is associated with

Table 2 ORs with $95 \%$ Cls of developing rheumatoid arthritis (RA) overall, anti-citrullinated protein antibody (ACPA)-positive RA and ACPA-negative RA, among women with occupational exposure to textile dust compared with women unexposed to textile dust in the Malaysian Epidemiological Investigation of Rheumatoid Arthritis study

\begin{tabular}{|c|c|c|}
\hline & Cases/controls & OR $(95 \% \mathrm{Cl})^{*}$ \\
\hline \multicolumn{3}{|c|}{ Occupational exposure to textile dust } \\
\hline \multicolumn{3}{|l|}{ RA overall } \\
\hline Unexposed & $622 / 647$ & Referent \\
\hline Ever exposed & $41 / 15$ & $2.8(1.6$ to 5.2$)$ \\
\hline \multicolumn{3}{|c|}{ ACPA-positive RA } \\
\hline Unexposed & $399 / 647$ & Referent \\
\hline Ever exposed & $23 / 15$ & 2.5 (1.3 to 4.8$)$ \\
\hline \multicolumn{3}{|c|}{ ACPA-negative RA } \\
\hline Unexposed & $223 / 647$ & Referent \\
\hline Ever exposed & $18 / 15$ & $3.5(1.7$ to 7.0$)$ \\
\hline
\end{tabular}

*Adjusted for age group, geographical area, educational levels and ethnicity.
Table 3 Risk of developing rheumatoid arthritis (RA) in women with different combinations of occupational textile dust exposure and shared epitope (SE) genes compared with women who reported no exposure to textile dust and carrying no SE genes, Malaysian Epidemiological Investigation of Rheumatoid Arthritis study*

\begin{tabular}{|c|c|c|}
\hline No SE & & Any SE \\
\hline $\mathrm{Ca} / \mathrm{Co}$ & OR $(95 \% \mathrm{Cl})$ & OR $(95 \% \mathrm{Cl})$ \\
\hline
\end{tabular}

Occupational exposure to textile dust

RA overall

$\begin{array}{llllc}\text { Unexposed } & 376 / 545 & \text { Referent } & 244 / 102 & 3.4(2.7 \text { to } 4.3) \\ \text { Ever exposed } & 24 / 14 & 2.5(1.3 \text { to } 4.9) & 17 / 1 & 25.1(3.3 \text { to } 189.5)\end{array}$

\begin{tabular}{|c|c|c|c|c|}
\hline & & & & AP: $0.8(0.4 \text { to } 1.2)^{* *}$ \\
\hline \multicolumn{5}{|l|}{ ACPA-positive RA } \\
\hline Unexposed & $201 / 545$ & Referent & $198 / 102$ & 5.1 (4.0 to 6.6 ) \\
\hline \multirow[t]{2}{*}{ Ever exposed } & $9 / 14$ & $1.8(0.8$ to 4.2$)$ & $14 / 1$ & 39.1 (5.1 to 297.5 ) \\
\hline & & & & AP: $0.8(0.5 \text { to } 1.2)^{* *}$ \\
\hline ACPA-negative RA & $175 / 545$ & Referent & $46 / 102$ & 1.5 (1.1 to 2.0$)$ \\
\hline Unexposed & $15 / 14$ & 3.3 (1.6 to 6.9$)$ & $3 / 1$ & 9.3 (1.0 to 89.4$)$ \\
\hline Ever exposed & & & & AP: 0.6 (-0.4 to 1.6$)$ \\
\hline
\end{tabular}

*All estimates adjusted for age group, geographical area, educational levels and ethnicity.

${ }^{* *} \mathrm{p}<0.0001$

ACPA, anti-citrullinated protein antibody; AP, attributable proportion due to interaction; $\mathrm{Ca} / \mathrm{Co}$, case/control.

risk for both ACPA-positive and ACPA-negative disease, whereas smoking and silica provide risk for only ACPA-positive disease. 82021 We do not have any mechanistic hypothesis for this difference and can only speculate that textile dust exposure may have a more general effect on immune activation, also in ACPA-negative disease than is the case for cigarette smoke and silica dust exposure. Whether there is an interaction between textile dust and smoking with regard to risk of developing ACPA-positive RA, as is the case for silica, ${ }^{20}{ }^{34}$ could not be studied in the present investigation since virtually all women never had smoked.

The properties of textile dust content differ depending on the fabric, the manufacturing and processing of the material. For instance, the source of the dust may originate from both natural (eg, wool, cotton) and synthetic (eg, polyester, nylon) materials. $^{35}$ Also, a wide range of chemicals might be used to attain desirable properties of the fabric, like synthetic dyers, flame retardants, mineral lubricants and water repellents (International Agency for Research on Cancer). The association between textile dust and risk of RA might involve several potential disease mechanisms since the differing physicochemical properties of airborne dust affect where it deposits in the respiratory tract. $^{36}$

We further propose that natural or synthetic fibres in textile dust might explain an association between textile dust exposure and risk of RA. Due to their unique shape, fibres have been shown to penetrate deep into the lung, where they initiate an inflammatory response. ${ }^{37}$ However, many textiles contain natural organic fibres and the health effects from natural organic fibres are not as strongly linked to lung disease as inorganic fibres. ${ }^{38}$

Based on the reasoning above, the participants in MyEIRA may, therefore, have encountered both known and so far to us unknown agents associated with RA either through the textile dust itself or through other confounding hazardous exposures in their work environment during the manufacturing and processing of the textile (like mineral dusts or other chemical dusts). 
A

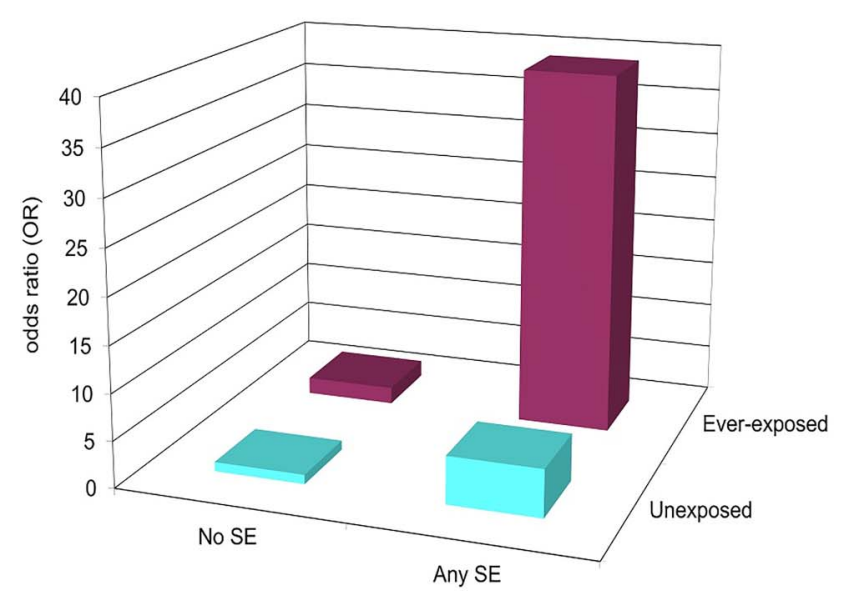

B

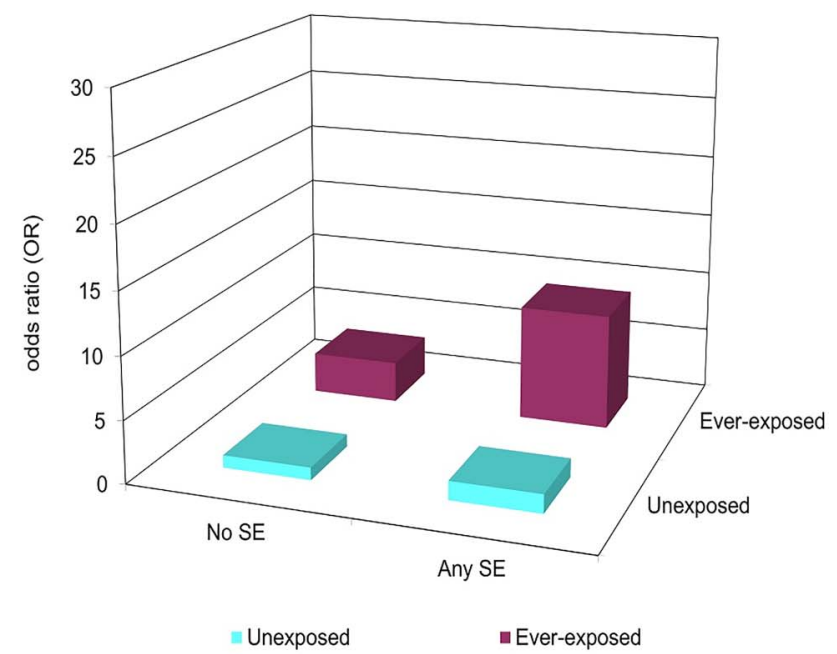

Figure 1 ORs of developing (A) anti-citrullinated protein antibody (ACPA)-positive and (B) ACPA-negative rheumatoid arthritis (RA) for different combinations of occupational exposure to textile dust and shared epitope (SE) alleles compared with those never exposed to textile dust and having no SE alleles.

Asbestos is another potential airborne exposure among textile workers. ${ }^{39} 40$

Another potential mechanism behind the demonstrated association between exposure to textile dust and risk for RA is bacterial agents that can be found in textile dust, especially endotoxin, which is a bacterial agent produced by all Gram-negative bacteria and is believed to cause respiratory diseases in textile workers by generating an inflammatory response in the lungs. ${ }^{24} 274142$ The present study design does not, however, allow us to further address this possibility.

A very interesting finding was the observation of a similar interaction between occupational exposure to textile dust and HLA-DRB1 SE in relation to ACPA-positive disease as has been seen for cigarette smoking and HLA-DRB1 SE. ${ }^{2}$ Here, we may speculate that similar events, that is, exposure to textile dust or smoking, may contribute to the production of citrullinated peptides, which, in the context of certain HLA alleles, may contribute to activation of anti-citrulline immunity in lungs. ${ }^{17}{ }^{18}$ Our statistical analysis did not identify this SE-textile interaction in ACPA-negative RA. This is in line with the lack of association between ACPA-negative RA and HLA-DRB1 SE in Malaysian RA. ${ }^{28}$ However, the power of this analysis was limited.

Our study has several advantages. The MyEIRA study is a population-based case-control study including incident cases. It contains information on both environmental and genetic risk factors. The response rate was high $(94.2 \%$ among cases, $96.2 \%$ among controls), which limits the risk of selection bias. Also, we recruited cases with short disease duration in an attempt to overcome differential misclassification of exposure, that is, that cases would recall their previous exposures differently from the controls. RA cases were selected by rheumatologists based upon their medical records, and the median duration of disease among the cases was 1 year with an IQR of 2 years. Thus, the inclusion of early RA cases gives an advantage that the patients are less likely to have had time to change their occupation due to RA manifestations, which possibly may influence the quality of the reported information on occupational exposures. However, we do not believe that recalling occupational exposures was difficult neither among cases nor among controls, and therefore, differential misclassification of textile dust exposure most probably is marginal and the possible non-differential misclassification that may have occurred would tend to bias our estimates towards the null value.

The study used the 1987 ACR criteria for the diagnosis of $\mathrm{RA}^{16}$ as the investigation started before the new 2010 European League Against Rheumatism/ACR criteria were introduced. The frequency of ACPA-positive RA was 63\%, which is well in line with data from other similar cohorts, including the Swedish EIRA study. ${ }^{43}$ A potential disadvantage is that some cases of RA in the selected areas may not have been included, thus generating a potential selection bias. Provided the design of this study, we consider such missing inclusion to be due mainly to administrative reasons, such as high burden of work and change of personnel (that are not informed about the study) and most probably not related to textile dust exposure. We thus believe that bias due to misclassification of disease does not constitute a major bias in this study.

We did not collect data on potentially harmful chemical hazards present in the textile industry, such as other organic dusts or organic solvents. Moreover, we do not know how many of the female textile workers conducted their work from home. Working with textiles in a home environment or an industrial environment might affect the likelihood of being exposed to chemicals that possibly may act as confounders. Passive smoking is theoretically another exposure that may have confounded the estimated association between textile dust and RA. There is, however, no reason to believe that women exposed to textile dust are more exposed to passive smoking than women that are not exposed.

The genetic heterogeneity in our multiethnic study population for MyEIRA study is a concern. In order to reduce this problem, we performed stratified analyses by ethnicity and could demonstrate that all the ethnic groups showed similar trends towards the risk of developing RA, although the limited power did not permit separate formal analysis in each ethnic group.

\section{CONCLUSION}

We observed an association between occupational textile dust and risk of developing RA. The high risk of developing ACPA-positive RA among HLA-DRB1 SE-positive individuals exposed to textile dust, and the significant gene-environment interaction between HLA-DRB1 SE and textile dust supports the hypothesis that various lung exposures may play an important role in the aetiology of RA. The increased risk also in 
ACPA-negative RA where there is no link to HLA-DRB1 SE indicates, however, that also other mechanisms may be involved, which have to be further investigated. From a public health perspective, our results imply that efforts should be considered to reduce the incidence of RA by reducing occupational exposure to textile dust.

Acknowledgements The authors would like to thank the Director General of Health, Malaysia, for supporting the work described in this paper. Special thanks to the members of MyEIRA study group and the rheumatologists: Heselynn Hussein, Wahinuddin Sulaiman, Ing Soo Lau, Suk Chyn Gun, Nor Suhaila Sharil, Eishwary M, Mohd Shahrir Said, Ainon Mokhtar, Azmillah Rosman, Muhaini Othman for their dedication and excellent assistance in this study. The authors truly value the patients and controls for their great participation.

Collaborators MyEIRA Study Group: Heselynn Hussein; Wahinuddin Sulaiman; Ing Soo Lau; Suk Chyn Gun; Nor Suhaila Sharil; Eishwary M; Mohd Shahrir Said; Ainon Mokhtar; Azmillah Rosman; Muhaini Othman.

Contributors CLT had full access to all data in this study and take responsibility for the integrity of the data and the accuracy of the data analysis. CLT, NAM and Al were responsible for the statistical analysis, interpreting the results and drafting the paper. CLT, NAM, LP, LA, LK, SM and CB conceived the study and participated in the design of the study and manuscript editing. CLT and LP performed serological and molecular genetics assay. CLT and LP take responsibility for the acquisition of the experimental data, analysis and interpretation of data. SM is the principal investigator of MyEIRA, LA and LK are the principal investigators of EIRA. All authors were involved in revising the paper critically for important intellectual content, and all authors approved the final version to be published.

Funding This study was supported by grants from Ministry of Health Malaysia (MRG-200512, JPP-IMR 07-046, JPP-IMR 08-006, JPP-IMR 07-017 and JPP-IMR 08-012) and from the Swedish National Research Council (DNR 348-2009-6468).

Competing interests None declared.

Patient consent Obtained.

Ethics approval The MyEIRA study was approved by the Medical Research and Ethics Committee of the Ministry of Health in Malaysia (KKM/JEPP/02 Jld.1 (86); (14)dlm.KKM/NIHSEC/08/0804/ MRG-2005-12).

Provenance and peer review Not commissioned; externally peer reviewed.

Data sharing statement The authors have no objection and are willing to share the data used for the current research article.

Open Access This is an Open Access article distributed in accordance with the Creative Commons Attribution Non Commercial (CC BY-NC 4.0) license, which permits others to distribute, remix, adapt, build upon this work non-commercially, and license their derivative works on different terms, provided the original work is properly cited and the use is non-commercial. See: http://creativecommons.org/ licenses/by-nc/4.0/

\section{REFERENCES}

1 Karlson EW, Deane K. Environmental and gene-environment interactions and risk of rheumatoid arthritis. Rheum Dis Clin North Am 2012:38:405-26.

2 Too CL, Yahya A, Murad S, et al. Smoking interacts with HLA-DRB1 shared epitope in the development of anti-citrullinated protein antibody-positive rheumatoid arthritis: results from the Malaysian Epidemiological Investigation of Rheumatoid Arthritis (MyEIRA). Arthritis Res Ther 2012;14:R89.

3 Källberg H, Ding B, Padyukov $L$, et al. Smoking is a major preventable risk factor for rheumatoid arthritis: estimations of risks after various exposures to cigarette smoke. Ann Rheum Dis 2011:70:508-11.

4 Mclnnes IB, Schett G. The pathogenesis of rheumatoid arthritis. N Engl J Med 2011:365:2205-19.

5 Padyukov L, Seielstad M, Ong RT, et al. A genome-wide association study suggests contrasting associations in ACPA-positive versus ACPA-negative rheumatoid arthritis. Ann Rheum Dis 2011;70:259-65.

6 Raychaudhuri S. Recent advances in the genetics of rheumatoid arthritis. Curr Opin Rheumatol 2010;22:109-18.

7 Klareskog L, Stolt P, Lundberg K, et al. A new model for an etiology of rheumatoid arthritis: smoking may trigger HLA-DR (shared epitope)-restricted immune reactions to autoantigens modified by citrullination. Arthritis Rheum 2006;54:38-46.

8 Lundström E, Källberg $H$, Alfredsson L, et al. Gene-environment interaction between the DRB1 shared epitope and smoking in the risk of anti-citrullinated protein antibody-positive rheumatoid arthritis: all alleles are important. Arthritis Rheum 2009;60:1597-603.

9 Padyukov $\mathrm{L}$, Silva $\mathrm{C}$, Stolt $\mathrm{P}$, et al. A gene-environment interaction between smoking and shared epitope genes in HLA-DR provides a high risk of seropositive rheumatoid arthritis. Arthritis Rheum 2004;50:3085-92.
10 Pedersen $M$, Jacobsen $S$, Klarlund $M$, et al. Environmental risk factors differ between rheumatoid arthritis with and without auto-antibodies against cyclic citrullinated peptides. Arthritis Res Ther 2006;8:R133.

11 Vessey MP, Villard-Mackintosh L, Yeates D. Oral contraceptives, cigarette smoking and other factors in relation to arthritis. Contraception 1987;35:457-64.

12 Lee HS, Irigoyen $\mathrm{P}$, Kern $\mathrm{M}$, et al. Interaction between smoking, the shared epitope, and anti-cyclic citrullinated peptide: a mixed picture in three large North American rheumatoid arthritis cohorts. Arthritis Rheum 2007:56:1745-53.

13 Michou L, Teixeira VH, Pierlot $\mathrm{C}$, et al. Associations between genetic factors, tobacco smoking and autoantibodies in familial and sporadic rheumatoid arthritis. Ann Rheum Dis 2008:67:466-70.

14 Pedersen M, Jacobsen S, Garred P, et al. Strong combined gene-environment effects in anti-cyclic citrullinated peptide-positive rheumatoid arthritis: a nationwide case-control study in Denmark. Arthritis Rheum 2007;56:1446-53.

15 Svärd A, Skogh T, Alfredsson L, et al. Associations with smoking and shared epitope differ between IgA- and IgG-class antibodies to cyclic citrullinated peptides in early rheumatoid arthritis. Arthritis Rheumatol 2015:67:2032-7.

16 Willemze A, van der Woude D, Ghidey W, et al. The interaction between HLA shared epitope alleles and smoking and its contribution to autoimmunity against several citrullinated antigens. Arthritis Rheum 2011;63:1823-32.

17 Catrina Al, Ytterberg AJ, Reynisdottir G, et al. Lungs, joints and immunity against citrullinated proteins in rheumatoid arthritis. Nat Rev Rheumatol 2014; 10:645-53.

18 Reynisdottir G, Karimi R, Joshua V, et al. Structural changes and antibody enrichment in the lungs are early features of anti-citrullinated protein antibody-positive rheumatoid arthritis. Nat Rev Rheumatol 2014;66:31-9.

19 Demoruelle MK, Weisman MH, Simonian PL, et al. Brief report: airways abnormalities and rheumatoid arthritis-related autoantibodies in subjects without arthritis: early injury or initiating site of autoimmunity? Arthritis Rheum 2012:64:1756-61.

20 Stolt P, Yahya A, Bengtsson C, et al. Silica exposure among male current smokers is associated with a high risk of developing ACPA-positive rheumatoid arthritis. Ann Rheum Dis 2010:69:1072-6.

21 Yahya A, Bengtsson C, Larsson $P$, et al. Silica exposure is associated with an increased risk of developing ACPA-positive rheumatoid arthritis in an Asian population: evidence from the Malaysian MyEIRA case-control study. Mod Rheumatol 2014:24:271-4

22 Christiani DC, Wang XR, Pan LD, et al. Longitudinal changes in pulmonary function and respiratory symptoms in cotton textile workers. A 15-yr follow-up study. Am J Respir Crit Care Med 2001;163:847-53.

23 Shi J, Mehta AJ, Hang JQ, et al. Chronic lung function decline in cotton textile workers: roles of historical and recent exposures to endotoxin. Environ Health Perspect 2010;118:1620-4.

24 Zuskin E, Mustajbegovic J, Schachter EN, et al. Respiratory symptoms and lung function in wool textile workers. Am J Ind Med 1995;27:845-57.

25 Poole JA, Wyatt TA, Oldenburg PJ, et al. Intranasal organic dust exposure-induced airway adaptation response marked by persistent lung inflammation and pathology in mice. Am J Physiol Lung Cell Mol Physiol 2009;296:L1085-95.

26 Khan AJ, Nanchal R. Cotton dust lung diseases. Curr Opin Pulm Med 2007;13: 137-41.

27 Lai PS, Christiani DC. Long-term respiratory health effects in textile workers. Curr Opin Pulm Med 2013;19:152-7.

28 Chun-Lai T, Padyukov L, Dhaliwal JS, et al. Shared epitope alleles remain a risk factor for anti-citrullinated proteins antibody (ACPA) — positive rheumatoid arthritis in three Asian ethnic groups. PLOS ONE 2011:6:e21069.

29 Guo J, Wu X, Too CL, et al. A replication study confirms the association of dendritic cell immunoreceptor (DCIR) polymorphisms with ACPA—negative RA in a large Asian cohort. PLOS ONE 2012;7:e41228.

30 Too CL, Murad S, Dhaliwal JS, et al. Polymorphisms in peptidylarginine deiminase associate with rheumatoid arthritis in diverse Asian populations: evidence from MyEIRA study and meta-analysis. Arthritis Res Ther 2012;14:R250.

31 Too CL, Rönnelid J, Yuslina YM, et al. Increased IgG rheumatoid factor-positivity in the Asian rheumatoid arthritis patients irrespective of ethnicity. Open J Rheumatol Autoimmune Dis 2014:4:43-51.

32 Yahya A, Bengtsson C, Lai TC, et al. Smoking is associated with an increased risk of developing ACPA-positive but not ACPA-negative rheumatoid arthritis in Asian populations: evidence from the Malaysian MyEIRA case-control study. Mod Rheumatol 2012:22:524-31.

33 Arnett FC, Edworthy SM, Bloch DA, et al. The American Rheumatism Association 1987 revised criteria for the classification of rheumatoid arthritis. Arthritis Rheum 1988:31:315-24

34 Stolt $\mathrm{P}$, Källberg $\mathrm{H}$, Lundberg I, et al. Silica exposure is associated with increased risk of developing rheumatoid arthritis: results from the Swedish EIRA study. Ann Rheum Dis 2005;64:582-6.

35 World Health Organization (WHO). International Agency for Research on Cancer (IARC) monographs on the evaluation of carcinogenic risk to humans: some flame retardants and textile chemicals, and exposures in the textile manufacturing industry. Lyon France 1990;48:1-345. 


\section{Clinical and epidemiological research}

36 World Health Organization (WHO). Hazard Prevention and Control in the Work Environment: Airborne Dust. WHO/SDE/OEH/9914. 1999:1-96.

37 Donaldson $\mathrm{K}$, Tran CL. Inflammation caused by particles and fibers. Inhal Toxicol 2002:14:5-27.

38 Järvholm B. Natural organic fibers-health effects. Rev Int Arch Occup Environ Health 2000;73(Suppl):69-74.

39 Loomis D, Dement JM, Wolf SH, et al. Lung cancer mortality and fibre exposures among North Carolina asbestos textile workers. Occup Environ Med 2009:66:535-42.

40 Pira E, Pelucchi C, Buffoni L, et al. Cancer mortality in a cohort of asbestos textile workers. Br J Cancer 2005;92:580-6.
41 Rylander R. Endotoxin and occupational airway disease. Curr Opin Allergy Clin Immunol 2006;6:62-6.

42 Thorn J. The inflammatory response in humans after inhalation of bacterial endotoxin: a review. Inflamm Res 2001:50:254-61.

43 Orellana C, Wedrén S, Källberg $\mathrm{H}$, et al. Parity and the risk of developing rheumatoid arthritis: results from the Swedish Epidemiological Investigation of Rheumatoid Arthritis study. Ann Rheum Dis 2014;73:752-5.

44 Greenland S, Rothman K, Lash T. Measures of effect and measures of association. In: Rothman KJ, Greenland S, Lash TL, eds. Modern epidemiology. Philadelphia, USA: Lippincott-Raven, 2008:74-83. 